\title{
English Language and Literature in English Integration into One Subject: A Case of Zambian Secondary Education System
}

\author{
Martin Banda, $\mathrm{PhD}^{1^{*}}$, Given Paul Kakoma ${ }^{2}$ \\ ${ }^{1}$ University of Edenberg Kitwe \\ ${ }^{2}$ Mbozi Day Secondary School Vubwi
}

\author{
*Corresponding Author: Martin Banda, PhD, University of Edenberg Kitwe
}

\begin{abstract}
English language is taught from grade 5 through to grade 12, and is used as a medium of instruction in all schools in Zambia. This is because it has been adopted as the lingua franca of Zambia, owing much to the ethnical situation where there are quite a number of languages. The language makes it easier to communicate in a cosmopolitan society as it becomes central both in the social and business lives of the citizenry. This language, and subject, is taught in schools to impart speaking, writing, reading and listening skills. Literature in English on the other hand is only taught from grade 10 to grade 12, and in tertiary level education. This subject imparts analytical skills coupled with poetry and drama. The subject includes entertainment and critical analysis skills development as some of its functions. The literature is written in English, hence the name. The learners are given an experience with several novels and plays and taught to analyse them by using literary devices. The researchers augment the need to integrate the two subjects so as to afford equal chances for the secondary school learners in order to impart skills missed by not learning literature in English.
\end{abstract}

\section{BACKGROUND}

Since time in memorial, the Zambian education system has necessitated that for one to have a fortuitous of going through the tertiary level education, they must pass a number of subjects and English should be among them. The grading system indicates that at least a credit pass is adequate for a pass mark.

Additionally, the subject roster has Literature in English, this is learned as an optional subject, meaning not every learner acquires this knowledge as there are a great number of other subjects like Metal work and Accounts, to name a few.

In between the lines, English language and Literature in English are related subjects, and there is a case to argue for the integration of the two, as the title of the article suggests. Hence, the reason for this article and the research taken.

So this paper is based on a research undertaken in Chipata District, in 2019, August-October. The reason for this research was to explore the perceptions of teachers and pupils of both subjects concerning their integration into one subject. This activity was based on a number of objectives, but this article will focus on one in particular.

\section{LITERATURE REVIEW}

The improvement of results being the sore of revisions and integration of curricula, the integration of these subjects would greatly improve results as earlier stated. Other schools of thought have had a similar say over the matter. Moody (1981:1) argued that:

In a second language situation, particularly one result of the rigiddivision between what is designated "literature" and all other kinds of writing is that the student begins to view his own ability to uselanguage as remote from or even incompatible with the uses oflanguage that he is studying.

Thus argues for the case that proficiency in language use and formation would be improved if these two are integrated as they give the learner the ability to use and understand language in connection 
with what is going on around other than separating lines of thought because one subject is separate from the other and viewed in different perspectives.

Brumfit (1982) also made reference to this situation by implying that the teaching of English as a second language should be integrated more with literature to enable the students see the relationship between the two subjects.

Realising the importance on Literature, the Zambian interim English syllabus of 1969 recommended that only students with a reasonable proficiency in English would be allowed to take literature.The rationale was that those with a 'less' ability may lack the linguistic ability to make meaningful response to the set book, although there is no such criterion nowadays but one might suspect that some loophole was not sealed for the notion to spread even to this age. Then a number of scholars argued against what one might term an 'elitist' practice. Stone (1964) argued that literature be made accessible to all students in schools, he argued that actually the weak learners needed literature more than the more proficient learners did. This rationale overlooked the importance of literature.

The researchers get their integration path from one or two types of integration, in this case, Connected and Webbed. These give us an idea of what we need to do. For this research paper and suggestion, teaching literary devices, excerpts from novels and plays, and so on, would need to be integrated into English language, so the connected and webbed modes help out, this would imply localising this integration. It is important as a country and the Curriculum Development Centre (C.D.C) to contextualize a curriculum. This is because the country's needs come before the needs of the global village. We can take the idea of integrating subjects that are similar as a point of reference to champion the idea of merging the two subjects. English and Literature in English are similar subjects and there is no need to separate them. The reasons for separating them are not valid as they just diminish the quality of subjects as they should be. The literature component of the subject would increase the level of critical thinking in the learners as one of the benefits of the subject is to nurture critical thinking in the learners. John Nowicki (as cited by Gina Contardi et al, 2000) supports this notion by stating the following;

There is a strong push to involve students in their learning, to let

them create their own understanding, to encourage critical thinking,

and to increase student's responsibility in schooling. Integrated

curriculum transfers this theory into practice (http://www.users.miamioh.edu/shermalw/ edp603_group3-f00.html)

Supporting this assertion in this instance, the literary techniques and devices such as metaphor, simile, hyperbole, personification, among them make sure this is the case in society. Therefore, to preserve them we must integrate them in the English language to make sure these skills such as critical thinking are preserved and used regularly.

An integration of English language and Literature in English has the potential to contribute to the development of both productive and receptive reading skills of students. This results from the realisation that literature in English is a use of language. Gurrey (1966) suggests that the student becomes morecertainly aware of their word's fullest and richest meanings as a result of this reading experience. The studentthus may learn to use these words himself more effectively and moreappropriately in different contexts.

Moody (1967),consolidated the importance of literature in second language learning when he stated that:

One of the powerful reasons for the inclusion of literature in thesecondary school curriculum is a means of extending and reinforcingstudent's command of the language both receptively and productively. (p75)

One linguist who also emphasizes on the importance of teaching Literature in English, or Literature in integration with Language is Marcus (as cited by TESOL blog, 2015). She shares a background of having taught ESL (English as a Second Language) at the University of California, which is predominately what is done in our case even if not as pronounced. She also ran a TESOL workshop, 
for 15 years, on integrating literature into language learning or studies. She also ran workshops internationally for the U.S. State Department on using literature for critical thinking and conflict resolution.

She is quoted to have stated the following on the importance of this integration by a guest author on a blog;

We're all wired to enjoy a good story with intriguing plotlines

and an individualprose style. So, it's a pity that many teachers

either ignoreorare unaware of thecreative possibilities that

literature offers for language learning (3).

(Marcus, $2015 \mathrm{http} / / / \mathrm{www} . e s q u i r e . c o m / e n t e r t a i n m e n t)$

In the blog, the author also talks about some of the ways of using novels or stories to teach critical thinking; encourage animated discussion; and hone vocabulary, grammar, and writing practice. In reading comprehension, the goal is to teach the learners to read critically. This requires carefully reading each story twice. The first reading helps students figure out the plot and deal with unfamiliar vocabulary and difficult syntax. The second reading gives them a chance to go deeper into themes and elements of style. To jumpstart their critical thinking, the students should be given open-ended questions to consider after they have completed the first reading. They must come to class ready to explain their answer with reference to the text. Questions should include the skills of sympathizing with character's actions, analysing if their feelings toward a character changes as they read the story, as well as predicting the ending. After this, we move on to the plot, theme, and style questions that are needed to understand and appreciate the story.

The importance of literature in oral communication is another point to be emphasized. Speaking is an area where literature really shines. When a story resonates with students, they cannot stop talking about it. Some ideas for getting a conversation going include; discussing the warm-up questions, talking about the themes raised by the story, taking a side on an issue and debate it with a partner, reenacting scenes from the stories.

The author also noted that grammar comes alive for students when they see it in action in an authentic context, by using examples from literary texts. Literature works particularly well as an opportunity for students to practice what they have previously learned. In vocabulary, the stories expand the students' vocabulary by introducing words in a memorable context, with little reliance on dictionaries. In writing, some of the best students in writing are those in literature classes. These should be encouraged to be both personal and analytical, using Imaginative writing such as keeping a diary in the life of a character; composing a new ending; writing a character profile, or even writing an original short story. (Marcus, 2015 on http://blog.tesol.org/literature-in-elt-integrating-literature-intolanguage-learning/)

These arguments as much as they serve to show the importance of teaching literature, they also show that aligning it with language serves the learner better than separating them. Therefore, the integration of the two subjects in the curriculum would serve and save both subjects diligently in achieving the aims of both the subjects.

In a research by Rahman (2018), the aim and objective of the research was to investigate the overall attitudes of tertiary level students to the use of literature in language classes. In addition, this research also addressed student preferences, their problems and prior experiences of studying literature in the language classroom. Quite similar to this study, only at different levels, one of the concluding statements was that, although they had encountered literary texts at some point of their education, the approach and exposure to these texts were not enough. Besides, most of the learners perceived literature as a complex and uninteresting instrument for learning language. These problems can be solved by selecting texts that would be suitable for majority of the students. However, as many students read literature occasionally, they appreciate literature for their personal pleasure without regard to its pedagogical integration. Nevertheless, this could be changed by emphasizing the importance of literature and this integration.

As it provides a context, learners can respond to it directly and the exploration and discussion of the content can make the learners motivated to the study (Brumfit\& Carter, 1986: 15). From the time 
when CLT (Communicative Language Teaching) emerged, most of the language programs focus on using utilitarian texts such as travel time tables, city plans, posters, advertisements, newspapers and magazine articles just to mention a few, which are not made for teaching purposes. Such materials give the learners exposure to the genuine use of language.

Additionally, being an authentic material literature can foster the acquisition of natural language, which eventually enhances their language proficiency and fulfil the practical need of learning language.

In addition, Lazar (1993) remarks that

"Literary texts enable the learners to understand how people belong to a particular culture behave in a particular situation. It familiarizes students with that particular social setting and provides a way of contextualizing the scenario. More interestingly, it can provide the learners insight into the relationships, emotions, attitudes of the people and gives them perception about the society" (p.17).

Therefore, the practical need of language learning is also fulfilled. In regard to this, Collie and Slater (1987) provides a remarkable thought-

A reader can discover their thoughts, feelings, customs, possessions; what they buy, believe in, fear, enjoy; how they speak and behave behind closed doors. This vivid imagined world can quickly give the foreign reader a feel for the codes and preoccupation that structures a real society (p.4).

Therefore, literature gives the learners an extensive exposure to the culture of target language, which can further contribute to their practical purposes of learning language. Therefore, this integration can help the learner acquire meaningful learning, and association.

Incorporation of literary texts in language learning can play a crucial role in increasing learners' motivation. Lazar (1993) indicates "literary texts as highly motivating and engaging because literature gives the students exposure to complex themes and unusual use of language" (p. 15). She further remarks, literary texts such as novels and short stories may be more engaging in that sense, it involves students in the suspense of unravelling the plot. It has been argued that literature is a particularly good source for developing students' abilities to infer meaning and to make interpretations (as cited in Lazar, 1993). Because of its multiple levels of meaning and demand that the reader/learner is actively involved in 'teasing out' the unstated implications and assumptions of the text.

Educators in related field agreed that literary texts are effective materials for improving both language skills (reading, writing, listening, speaking) and language areas (vocabulary, grammar and pronunciation). Ghosn (2002) mentions that literature is not only interesting but also it facilitates the integration of language skills.

Reading is one of the four basic language skills and good proficiency in reading is one of the primary goals of language learning. As literature demands careful inquiry of meaning and in-depth study, it can help improving learners reading proficiency.

According to McKay (1982); "An evaluation of reading proficiency rests on an understanding of

what is involved in the reading process" (p.530).

She further suggests that literature can foster the overall reading proficiency of the learners, which will contribute to achieve academic goals. Gajdusek (1988) also remarks that"reading as an active and two-way system of connecting incoming data with existing knowledge; of both language system and the world" (p.231).

In addition to that, literary texts are enriched sources, which have multiple levels of meaning. Literature often demands its reader or learners to involve actively with the text so that they can interpret the underlying meaning. Thus, it encourages learners to understand multiple ambiguities of the literary text and help them to develop their ability to infer the meaning from the text and relate it to the outside world (Lazar, 1993: 76). Widdowson (as cited in Spack, 1985) remarks; "as the study of 
literature demands study of meaning in depth, ithelps learners to develop an important feature of language learning, which is the ability to interpret a discourse" (p. 706).

He further notes that development of interpretative ability is important for the learners as this can be applied to a range of language uses, not only literary but also non-literary, both inside and outside the learning situation.

Spack (1985) points out that; "by interpreting texts and considering alternative interpretations, studentscome to understand in a fundamental way how meaning can be created through reading" (p.706).

Mckay (1982) also states that "reading necessitates the ability to interact with a text by decoding the language and comprehending the concepts presented" (531). This perspective of interaction also assumes the fact whether learners are willing to interact with the text, and thus involves motivational factors with it. She again suggests that "to the extent that students enjoy reading literature, it may increase theirmotivation to interact with a text and thus, ultimately increase their readingproficiency" (p.531).

Thus, the use of literary texts can improve reading skills of the learners, qualifying the idea that integration of the two subjects would improve performances.

Proponents of this related field have significantly acknowledged the contribution of literature in increasing learners' vocabulary. According to Collie and Slater (1987), "reading literary texts significantly increases learners' receptive vocabulary" (p.4). Gajdusek (1988) also notes that, if appropriate reading activities are provided while teaching literature, it can stimulate word skill and encourages meaningful vocabulary growth of the learners (p.235).

As literature presents natural language to its finest, thus it can foster vocabulary learning in context (Ghosn, 2002, p. 173). In this regard, Lazar (1996) remarks; "interpreting meaning from the context not only increase their vocabularybut also strengthens their understanding of how a word can be usedin different contexts" (p. 774).

Besides, a significant skill of inferring meanings of unfamiliar words will be developed (Hoque, 2006). According to Anderson and Nagy (1985), "one of the most effective vocabulary instructions is multiple exposures to words in a variety of oral and written contexts which fosters the vocabulary growth of the learners" (p.312).

In addition, knowledge of vocabulary and reading comprehension is also interconnected. Comprehension of a literary text can boost learners' vocabulary skill. Nagy and Herman (1985) suggested that comprehension of literary texts can provide conceptual base for understanding the meaning of new words. For the texts, which are comparatively difficult, Gajdusek (1988) suggests that "teachers should include some pre-reading vocabulary exercises; so that the learners do not face problems while reading the texts" (p.235). Thus, literature can foster language and vocabulary learning of the students.

\subsection{Criticisms}

However, regardless of various theoretical support for utilizing literature in the language programs or indeed integrating the two subjects, numerous critics provide arguments against it. Firstly, according to Topping (1968) "the primary demand of language learning is to improve basic language skills (reading, writing, speaking and listening) which; however, cannot be fulfilled by literature" (p.100). "It is also argued that study of literature will contribute nothing in developing learners' academic or occupational proficiency" (McKay, 1982: 529).Therefore, many educators feel that literary texts should be excluded from the language curriculum.

To those who are concerned about the utilitarian aim of language learning, Widdowson (1975, cited in Spack, 1982) points out that the study of literature develops a sharper awareness of the communicative resources of the language being learned; therefore, something important and useful can be learned from studying literary texts. He criticizes those who support the idea of excluding literature from the curriculum because of its alleged irrelevance to the purpose of language learning and create their own new fictions and texts to give the learners exposure to language usage. 
To the teachers and educationists who believe literary texts are not effective for enhancing learners' academic proficiency, McKay (1982) mentions; "for some students, literature may provide the affective, attitudinal and experiential factors which will motivate them to read. As such, literary texts can aid in the development of reading proficiency and in this way contribute to a students' academic and occupational objectives" (p.530).

Another common argument against using literature is that students may find or actually find it difficult. Topping (1968) notes that;" "the language of literature is syntactically complex for which learners may find it difficult to learn" (p.98).

In this regard, Gajdusek (1988) argues that,

It has been my personal experience that many ESL teachers eitherconsciously or unconsciously feel that "literature is too 'hard' for ESL students." Given the large number of language-teaching problemsthat they have to face, many do not bother to ask themselves why they feel this way; there seem to be more practical things to worry about. Thus, not having examined the "problem," they fail to discover the exciting communicative potential that the solution to the problem-oncearticulated-could yield (p.227).

Another criticism for using literary texts is its remote cultural perspective, for which learners may not be able to relate it with their own culture. Topping (1968) notes that, "literature of English language gives an insight to English culture, which is not needed for a second language learner to know, as the primary concern for his language learning is to improve his academic and communicative skills" (p.99). In response to this argument, Lazar (1996) remarks that literature gives the learners access to other cultures (p.774). She further points out; given the complicated relationship between literary works and the world, perhaps this access is more of a tantalizing glimpse of another culture than a mirror-like documentation of it" (Ibid).

The theories and arguments discussed in this chapter enabled the researcher to understand the pros and cons of integrating English language and Literature in English into one subject, which further helped to evaluate the attitudes of the teachers, students and officials of language. Besides, it also gave an insight on the effective methods that can be used to improve the performance of the two subjects in our education settings.

\section{METHODOLOGY}

The research methodology was descriptive, as it explained the scenario of the learning of both subjects and the respondents indicated how the phenomenon of integration would affect the performance of learners if that were to be put in place.

\subsection{Presentation of Findings}

The articles' objective was to explore if integrating English Language (EL) and Literature in English $(\mathrm{LiE})$ would improve the performance of the learners and subject.

The questions that were answered by the respondents through interact with questionnaires and interviews, were whether this integration would improve or worsen the performances with reference to the objective of the study.

\section{Integration - Improve performances}

Table1. Teacher opinions and reasons

\begin{tabular}{|l|l|l|}
\hline Reason & $\boldsymbol{F}$ & \% (out of 4 respondents) \\
\hline Balanced performance because subjects are related & 2 & 50 \\
\hline Improve reading skills & 4 & 100 \\
\hline
\end{tabular}

From the table above, 4 respondents or $33.4 \%$ of the teacher respondents, who thought integration of the subjects would improve performances.

$50 \%$ (2) of these respondents indicated that integration would improve performances of both subjects, and the learners, because performances in both components would be balanced. The reason is that the 
learners would be able to use features of both subjects to complement one another, therefore, bringing a realization of the subject's connectedness

Another reason given by $100 \%$ (4) of these respondents was that it would improve the learners reading skills. This is because they will be required to read widely and study texts in order to apply the necessary skills, which would apply well in both components, as compared to them being separate, hence treating them like different subjects all together.

Table2. Learner's opinions and reasons

\begin{tabular}{|l|l|l|}
\hline Reason & $\boldsymbol{F}$ & $\boldsymbol{\%}$ \\
\hline Help learners see relationship between subjects making it easy to understand & 26 & 37 \\
\hline Improved language use & 31 & 44 \\
\hline Reduce subject load & 4 & 6 \\
\hline Improve contact with book and stories & 9 & 13 \\
\hline
\end{tabular}

71 learners, representing $60 \%$ of the respondents, indicated that integration would improve performances of the subjects. They added on to this and gave the following reasons;

Firstly, 37\% (26) of these respondents believed that integration would help learners see the relationship between the two subjects, which would ultimately make language learning and use easy. This would also make the subject easy to grasp. They also indicated that this would reduce redundancy and repetition of concepts found in both subjects. In the FGD, FGD-P3 supported this by saying that;

It would improve English speaking because English is an official language.

FGD-P1 added;

It would improve because it would give access to every learner to read novels.

$44 \%$ (31) of these respondents echoed the reason that LiE would improve language use if learned more regularly; that is to say that the concepts in LiE make language learning practical, as well as imparting good moral and the exposure associated with English language.

They also indicated that integration would reduce the load of subjects learned, which was suggested by $6 \%$ (4) of these respondents, hence giving enough time to learners for research, practice and discovery of new knowledge and trends, guided by the concepts of the would be subject.

Last but not the least, 13\% (9) of the respondents indicated that the texts read in LiE can be used as excerpts in Comprehension and Summary exercises or lesson, increasing contact and analysis of the selected texts. In the end this would help the learner make learning connected and meaningful.

\subsection{Interviews}

The SESO also indicated, in relation to the criteria used to integrate the local languages and French, that it was important to realise that the two parts, grammar and literature, should go hand in hand and complement each other. This in turn makes the learners see the importance and relatedness of both components. This also makes Literature attractive to the learners. The respondent mentioned that this criteria and realization should be considered for EL and LiE as they are similar and there is no need to separate these two subjects but learn them as one.

\section{Integration-Worsen Performances}

Table3. Teacher opinion and reasons

\begin{tabular}{|l|l|l|}
\hline Reason & F & \% (out of 8 respondents) \\
\hline Bad results in one subject would affect the other & 3 & 38 \\
\hline Both subjects are too wide bulky & 4 & 50 \\
\hline Principles of EL are stricter than LiE & 1 & 13 \\
\hline Lack of material & 1 & 13 \\
\hline
\end{tabular}

From the table above, 8 respondents or $66.6 \%$ of the respondents, who were teachers, thought that integration of the two would worsen performances of the learners.

These gave the following reasons: firstly, 38\% (3) of these respondents thought integration would worsen performances in both subjects because most learners are good in one of the two subjects, and 
so their deficiencies in the other would affect the other subject, as well as affect their interest in both.In the FGD, P4 echoed this sentiment by saying that;

It will be bad because some pupils are good in English and bad inLiterature in English, so Literature in English will affect English.

This is also coupled with the fact that some teachers are not as competent in LiE as they are in EL, so this would affect the subject when they fall short in the literature component of the subject.

Secondly, 50\% (4) of these respondents thought that both subjects are wide, so integrating them would mean shedding off some important components from each subjects, or alternatively making the would be subject bulky. This would also compromise the timetabling, already most schools have less time to accommodate new components on the time table, and quite a lot of time would be needed to cover this new integrated subject.

Additionally, 1 respondent representing 8\% indicated that the principles of EL are stricter and complicated than LiE, so integration would create a difficult situation because of this aspect.

1 respondent, representing $8 \%$ also indicated that another reason leading to poor performance is the shortage of learning material in $\mathrm{LiE}$, so this would negatively affect the integration of the subjects.

Table4. Learner opinions and reasons

\begin{tabular}{|l|l|l|}
\hline Reason & $\boldsymbol{F}$ & $\boldsymbol{\%}$ \\
\hline LiE has too many books to cover & 6 & 13 \\
\hline LiE is confusing & 20 & 42.5 \\
\hline Both subjects are bulky & 20 & 42.5 \\
\hline Lack of material in schools & 1 & 2 \\
\hline
\end{tabular}

The learner respondents who believed it would worsen performances, who were 47, representing 40\% of the respondents, indicated that integration would worsen performances in both subjects, and gave the following reasons:

$13 \%$ (6) of these respondents believed that LiE has too many books to cover, which would be difficult to cover if integrated with EL. This would mean less coverage and experience, resulting into bad results and what is termed 'half-baked' learners. About $42 \%$ (20) of these also indicated that LiE is confusing because of the concepts and terminologies; these would create difficulties as both subjects can be demanding.

A reason given by $42.5 \%$ (20) of the respondents was that both subjects are bulky in content on their own, so integration would mean a much more bulky subject that is difficult to cover at the end of their secondary school life. This reason was amplified by the fact that there are shortages of material in schools, indicated by $2 \%$ (1) of the respondent, who also added that integration would affect learners who were good in one subject negatively, as the 'difficult' subject would affect the final results. In the Focus Group Discussion, P4 actually consolidated this notion of integration worsening performances by citing the integration of History, Civics and Geography into Social Studies, saying;

\section{Joining English and Literature will make it difficult to understand \\ and even being unable to work properly as it means after40 minutes \\ another subject and teacher come in to teach and yet pupils write it \\ as one subject. This is even more confusing when studying.}

\section{DISCUSSION OF FINDINGS}

These two subjects are taught separately and that has proved to be problematic as there are no teachers solely qualified in literature in English, but in the Zambian scenario, the teachers qualified in English language are required to teach it as it is part of their training at tertiary level, hence, the study at hand. The study aimed to explore the possibility of merging or integrating the two subjects in order curb a number of problems that have emerged due to them being separated. Literature in English being an 'optional' subject has become problematic as most learners and teachers alike shun it because it is termed as a difficult subject. This has resulted in poor attendance during lessons, low sitting numbers 
at examination and the 'slow death' of the subject. The importance of the subject is evidenced by the description in the Literature in English grade 10-12 syllabus, which partly states that Literature study involves reflecting, valuing, choosing, responding, takinga stand in life of complex issues. Sharpening the students' understanding of issues in general as well as enriching their thought.

This assertion clearly indicates the importance of the subject and cannot be over stated. This importance is further stated by this description by the ECZ chief examiner in their report on examinations in 2017, who indicated that; Literature in English is a critical subject in the appreciation of all subjects. This is not a superfluous assertion. All the other subjects use a language but it is literature that puts the language in context. Language needs a context and literature is that context. A natural scientist, social scientist, mathematician... all will need literary abilities to communicate their subjects (Examination Council of Zambia, 2017).

Unfortunately, negative reviews and analyses have characterized the performance of the subject during both normal learning and examinations, hence the need to take action to save the subject and its important facets. The negative performance is evidenced by the many reports from the Examination Council of Zambia (E.C.Z.) ranging from 2015 to 2018. For example, the report of 2016 indicated that both subjects actually performed the worst among the subjects on the roster. The report also indicated the candidature absenteeism and mean scores of Literature in English, which are not impressive, stating that candidature in Literature in English increased in the period 2015 to 2016. The mean percentage was quite low and the number of absentees and those attaining a zero score had increased. (ECZ 2016 performance report Literature in English and English Language May 2017)

This information compared to other subjects is worrying and needs attention at the earliest. These results can be compared even across a number of years. The 2017 examination performance booklet indicated that Literature in English performed worse than other subjects in the Department of Literature and Languages, stating that;

...Silozi had the highest number of candidates obtaining distinctions at 13.94percent. This was followed by Luvale at 12.54 percent. The lowest proportion of candidates obtaining distinction in theLiterature and Languages category was observed in Literature in English $(6.0 \%)$. High failure rate were observed in Literature inEnglish $(37.66 \%)$ and Icibemba (17.51\%).

The report also suggested that the candidates' poor performance in Literature in English and Icibemba needs to be interrogated in order to dig out factors responsible for this scenario. Hence, making it important to carry out measures to rectify this situation.

This discussion mainly concentrates on the integration of the two subjects as the objective states. This follows the integrated learning theory, which states that;

Integrated studies involve bringing together traditionally separate subjectsso that students can grasp a more authentic understanding. This approach allows learners to explore, gather, process, refine and present information about topics they want to investigate without the pressure of traditional learning (Pigdon and Woolley, 1992)

The study ultimately brought out the views of the teachers and learners involved in the learning of the two subjects. The main questions to be answered were if integrating of the two subjects would worsen or improve current performances. The responses ultimately led to the understanding of the current status quo in terms of general performance and examination absenteeism and attendance during the Literature in English exams.

Lazar (1996) also mentions that: The study revealed that quite a number of respondents, among the learners, thought that integrating the two subjects would improve performances because ultimately the two subjects are related and quite the same, this would also improve their language proficiency. Their teachers also added on to this by attesting that integration would balance the performance of both subjects, meaning that they would complement each other, as well as improve the language skills as earlier alluded to. The reason being that literature offers a vast array of text from different situations and cultures. These sentiments are echoed by Claire Kramsch (1993) who remarks; if, however, 
language is seen as social practice, culture becomes very core of language teaching. Cultural awareness must then be viewed both as enabling language proficiency and as being the outcome of reflection on language proficiency.

Another advantage of using literary texts in the classroom is that theyprovide students with access to other cultures. Given the complicated relationship between literary works and the world, perhaps this access is more of a tantalizing glimpse of another culture than a mirror-like documentation of it. Collie and Slater (1987) remark, Literature is authentic material. By what we simply mean that most works ofliterature are not fashioned for specific purpose of teachinga language. Then Ghosn (2002) adds; being an authentic material literature provides a meaningful context for language learning.

Additionally, the respondents also revealed that this would improve the reading culture as the learning process would introduce many more books to read, assimilate and understand. However, the study also revealed that a good number of respondents thought this idea of integration would actually worsen the performance of both subjects because the following reasons; this would make the wouldbe subject quite bulky. This is because both subjects, on their own, are complicated and bulky, so integrating them would only form a much bulkier subject and this would definitely compound the already dire situation. Some respondents decided to dissect the two subjects and compare; they attested that English Language has much stricter principles than Literature in English and needed to be learned on its own to understand it better as compared to integrating it with another subject. This was also echoed by Czerniaket al (1999), who stated the following teacher knowledge of the subject areas presents a (second), parallel problem. Many teachers, whether generalist or specialists simply do not have the knowledge to teach for depth in more than one field (subject).

Another reason revealed in the study was that pertaining to logistical matters; the respondents indicated the lack of learning material mainly in LiE would make integration difficult. The subject has very few and scarce material in schools and on the market, so this would affect the whole integration process and worsen performances as schools would be scrambling for material to cater for the needs of the whole component.

However, these finding that indicate that integration would worsen the performances of the learners can be rejected with a much bigger picture of adequate preparation through the valid process of curriculum development. Which requires, at least, a needs assessment and pilot project to curb the problems of the lack of material. That is also to say funding, planning and consultations need to be in place. The larger picture that should be considered is if a process provides meaningful learning to the learner, and integration is such a process.

Fogarty (1991) consolidates the idea of integration, generally, by explaining that this approach purposefully brings together the skills from different sets of subjects that are similar. This in turn develops a powerful understanding of ideas and key areas of concern and learning. The idea is that an integrated approach ensures meaningful learning for both the teachers and learners.

Other proponents of integration like Humpreys et al (1981) indicated that such a study broadens the learner's knowledge in various subjects related to each other, and in connection with the environment. They also saw that humanities, communication arts, to mention but a few, were linked in so many ways. These are facets of bot Literature in English and English Language. Echoing these thoughts, Shoemaker (1989) states that education that is organized in such a way that it cuts across subjectmatterlines, bringing together various aspects of the curriculum into meaningful association to focus upon broad areas of study. It views learning and teachingin a holistic way and reflects the real world, which is interactive.

Bringing the argument back home, Stone (1964) argued that literature should be made accessible to all students in schools; he also argued that a lot of weak learners would benefit more from learning literature more than the more proficient learners. An integration of English language and literature in English has the potential to contribute to the development of both productive and receptive reading skills of students. Gurrey (1966) argued that the result of this reading experience is that the student becomes more certainly aware of their word's fullest and richest meanings. The student thus may learn to use these words himself more effectively and more appropriately in different contexts.

Moody (1967) also thought that literature is important for the school curriculum because it is a means of extending and reinforcing student's command of the language both receptively and productively. 


\section{CONCLUSION}

Conclusively, we can state that literature in English is as an important subject as any other subject, but with it 'dying' gradually, there is a need to intervene. In 'dying' gradually, we mean that a very large number of learners are not or have never learned it, and yet it has proven to be a catalyst for good performances, and some schools have dropped it all together. So to preserve and save the subject and its important components, integration would help both the subject and pupil performances greatly.

\section{REFERENCES}

[1] Brumfit, C.J. (1982), Literature in Foreign language teaching: an overview, D. Pickett ed., Literature in Foreign Language Teaching, London: The British Council, 15-20

[2] Brumfit, C., \& Carter, R. (Eds.). (1986). Literature and language teaching. Retrieved from https://books.google.com.bd/books?hl=en\&lr=\&id=9p1n_CCYARUC\&oi=fnd\&pg=PR9\&dq=literature+i $\mathrm{n}+$ language+teaching \&ots=aczToewI57\&sig=M8rkr6sHcWXeXb9t4zOfYA_YW0\&redir_esc=y\#v=onepage\&q=literature\%20in\%20language\%20teaching\&f=false

[3] Collie, J., \& Slater, S. (1987). Literature in the language classroom; A resource book of ideas and activities. Cambridge: Cambridge University Press.

[4] Gajdusek, L. (1988). Toward wider use of literature in ESL: Why and how. TESOL Quarterly, 22(2), 227-257.

[5] Retrieved from http://www.jstor.org/stable/3586935

[6] Gina Contardi, Michelle Fall, Gina Flora, Jodi Gandee and Carrie Treadway,(2000) Integrated Curriculum: A Group Investigation Project, EDP 603, Fall.

[7] Retrieved from http://www.users.miamioh.edu/shermalw/edp603_group3-f00.html

[8] Ghosn, I. K. (2002). Four good reasons to use literature in primary school elt. ELT Journal, 56(2), 172-179.

[9] Gurrey, P. (1966), Teaching English as a Foreign Language, London: Longmans

[10] Hoque, E. (2007). The Use of Literature in Teaching English as a Foreign Language (TEFL).

[11] Harvest, 22, 1 -28.

[12] Retrieved from https://www.researchgate.net/

[13] Humphreys, A.; Post, T.; and Ellis, A. (1981) Interdisciplinary Methods: A Thematic Approach. Santa Monica, CA: Goodyear Publishing Company.

[14] Kramsch, C. (1993). Context and culture in language teaching. New York, Oxford University Press.

[15] Lazar, G. (1993). Literature and language teaching. New York, Cambridge University Press.

[16] Lazar, G. (1996). Exploring literary texts with the language learner. TESOL Quarterly, 30(4), 773-776.

[17] Retrieved from http://www.jstor.org/stable/3587934

[18] McKay, S. (1982). Literature in the esl classroom. TESOL Quarterly, 16(4), 529-536. Retrieved From http://www.jstor.org/stable/3586470

[19] Moody, H.L.B. (1967), School Certificate Literature, West African Journal of Education. Vol. 11 (2), 75-78

[20] Moody, J. (1981), the teaching of Literature in a second language, Ngoma, vol 1(1), 5-35.

[21] Nagy, W. E., Herman, P. A., \& Anderson, R. C. (1985). Learning Words from Context. Reading Research Quarterly, 20(2), 233-253.

[22] Retrieved from https://www.jstor.org/stable/747758

[23] Robin Forgaty(1991), How to Integrate the Curricula, Illinois: Skylight Publishing inc.

[24] Shoemaker, B. (1989), "Integrative Education: A Curriculum for the Twenty-First Century." Oregon School StudyCouncil 33/2

[25] Spack, R. (1985). Literature, reading, writing, and ESL: Bridging the gap. TESOL Quarterly, 19, 703-721.

[26] Topping, D. M. (1968). Linguistics or Literature: An Approach to Language. TESOL Quarterly, 2(2), 95100. Retrieved from https://www.jstor.org/stable/3586085 


\section{AUTHORS' BIOGRAPHY}

Given Paul Kakoma, is a teacher of English language and Literature in English in the Ministry of General Education (MoGE). He holds a Bachelor of Arts in Education degree from the University of Zambia (UNZA) and a Master of Education in Curriculum Studies degree fromMulungushi University. His research interests are in curriculum, language, literature, philosophy and governance.

Martin Banda, is a Director, Research and Postgraduate Studies at University of Edenberg-Zambia. He holds PhD and MA:Ed in Sociology of Education from the University of Zambia, a Bachelor of Arts in Education from the Catholic University of Eastern Africa. His research interests are in Sociology of Education, Education and Society, The Teacher and the Community, Sex Education, Curriculum studies and Teacher Education.

Citation: Martin Banda, PhD, Given Paul Kakoma. " English Language and Literature in English Integration into One Subject: A Case of Zambian Secondary Education System " International Journal of Humanities Social Sciences and Education (IJHSSE), vol 7, no. 6, 2020, pp. 75-86. doi: http://dx.doi.org/10.20431/23490381.0706009.

Copyright: (1) 2020 Authors. This is an open-access article distributed under the terms of the Creative Commons Attribution License, which permits unrestricted use, distribution, and reproduction in any medium, provided the original author and source are credited. 